\title{
Siberian silkmoth outbreaks surpassed geoclimatic barrier in Siberian Mountains
}

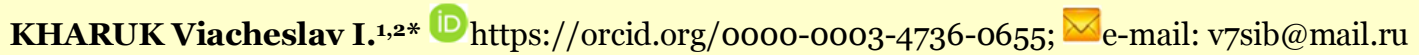

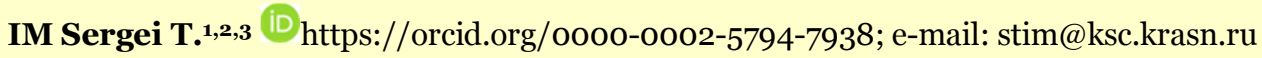 \\ SOLDATOV Vladimir V.4 iD https://orcid.org/oooo-ooo1-8454-3077; e-mail: Vladimir.soldatow24@yandex.ru \\ ${ }^{*}$ Corresponding author \\ 1 Sukachev Institute of Forest, Federal Scientific Center, Russian Academy of Science, Siberian Branch, Academgorodok \\ 5o/28, Krasnoyarsk, 660036 Russia \\ 2 Siberian Federal University, Svobodny str.79, Krasnoyarsk, 660041 Russia \\ 3 Reshetnev Siberian State University of Science and Technology, Krasnoyarsky rabochy str. 31, Krasnoyarsk, 660014 Russia \\ 4 Russian Center of Forest Protection, Academgorodok 50A/2, Krasnoyarsk, 660036 Russia \\ Citation: Kharuk VI, Im ST, Soldatov VV (2020) Siberian silkmoth outbreaks surpassed geoclimatic barrier in Siberian \\ Mountains. Journal of Mountain Science 17(8). https://doi.org/10.1007/s11629-020-5989-3
}

(C) Science Press, Institute of Mountain Hazards and Environment, CAS and Springer-Verlag GmbH Germany, part of Springer Nature 2020

\begin{abstract}
Siberian silkmoth (SSM, Dendrolimus sibiricus Tschetv.) is the most important defoliator of Siberian pine (Pinus sibirica Du Tour) and fir (Abies sibirica Ledeb.) stands. Warming-induced SSM outbreaks are one of the major driving factors of successions within the taiga zone. It is suggested that climate change impacted the SSM range and life cycle. We analyzed the migration of alpine and northerly SSM outbreak boundaries in Siberia and the impact of the climate variables and topography on the outbreak dynamics. We used time-series scenes (multispectral data, and vegetation indexes EVI and NDII) in combination with field studies, climate variables, and GIS techniques. We found that SSM outbreaks in the area of alpine boundary shifted about $370 \mathrm{~m}$ uphill since the mid of 1950. The outbreak onset was promoted by increased dryness and active temperatures and decreased root zone moisture content in the spring-early summer period. The terrain topography strongly affected SSM outbreak onset and dynamics. Initially, the outbreak was located at the middle elevations on the gentle concave southeastern slopes, which are the favorable insect
\end{abstract}

Received: $16-\mathrm{Jan}-2020$

Revised: 24-Apr-2020

Accepted: 02-Jun-2020 habitats between outbreaks. Then the outbreak expanded uphill and downhill, to steeper slopes, and both concave and convex terrains. Alongside with elevation range expansion, SSM surpassed its northern historical outbreak boundary: the potential outbreaks' boundary moved about $300 \mathrm{~km}$ northward. Climate warming contributes to SSM migration into former outbreak free conifer stands located in highlands and at northern latitudes.

Keywords: Insect outbreaks; Remote sensing monitoring; Insect ranges expansion; Siberian silkmoth; Forest health; Conifer mortality

\section{Introduction}

Siberian silkmoth (Dendrolimus sibiricus Tschetv., hereafter SSM) is the most important defoliator of Siberian "dark needle conifer" taiga stands composed of Pinus sibirica Du Tour and Abies sibirica Ledeb. These economically valuable species ranged from Mongolian border up to Arctic Circle, and occupied areas of 3.8 million $\mathrm{km}^{2}$ and 4 million $\mathrm{km}^{2}$, correspondingly, and often formed mixed stands (Koropachinskiy and Vstovskaya 
2002). Periodic SSM outbreaks were one of the major factors of these forests' successions. The maximal described stands' mortality (about 2,500,000 ha) referred to the catastrophic outbreak in 1953-1957 (Kharuk et al. 2003). The other important consequences of SSM outbreaks were an increase in the fire frequency and burned area (by 10 times; Kharuk and Antamoshkina 2017).

This insect feeds preferably on needles of Siberian pine and fir (main hosts); at the peak of the outbreak, insects feed on spruce (Picea obovata), Scotch pine (Pinus sylvestris) and even grass. SSM outbreaks were also observed within larch (Larix spp.) stands, although larches are more resistant to defoliation. SSM larva density during the endemic phase is less than one per tree, whereas at the peak of the outbreak that number reached 20,000 per tree (Kondakov, 2002). The range of this species spreads up to high northern latitudes; thus moth findings described at $\sim 63^{\circ} \mathrm{N}$ (Kondakov 1974). Meanwhile, the maximal described outbreak boundary was located at $60^{\circ} \mathrm{N}$ (Kharuk et al. 2018b).

It is expected that global warming may stimulate insect population, increase outbreak frequency and range (de la Giroday et al. 2012; Seiter and Kingsolver 2013; Kolb et al. 2016). That hypothesis is supported by observations of the spruce budworm northward expansion into boreal American forests (Pureswaran et al. 2015), gypsy moth increased range in Canada (Thompson et al. 2017), and Douglas-fir tussock moth expansion into the southwestern U.S. and northern Mexico forests (Coleman et al. 2014). Although insect outbreaks occurred also in former epoch (Alfaro et al. 2010), warming and increased aridity are one of the causes of Dendroctonus spp and Dendrolimus pini catastrophic outbreaks in North American and German forests (Haynes et al. 2014; Bentz et al. 2010; Weed et al. 2013). Similarly, in Russia, periodic droughts stimulated bark beetle (Polygraphus proximus Blandford) outbreaks that caused extensive ( $>500,000$ ha) fir mortality in Siberia (Kharuk et al. 2019). The alpine and northern silkmoth outbreak ranges are limited by cold temperatures (Kondakov 2002). Thus, Rojkov (1965) found that the northern range of SSM outbreaks approximated by sum of active temperatures $\left(t>+10^{\circ} \mathrm{C}\right.$ ) equal to $\sim 1200^{\circ} \mathrm{C}$.
Observed air temperature increase which is especially pronounced in the boreal zone may facilitate SSM expansion into habitats formerly considered as unsuitable (e.g. Pureswaran et al. 2015). That was observed during the latest catastrophic SSM outbreak (2016-2018 yrs.) which moved northerly and caused conifer mortality covering over 800,000 ha (Kharuk et al. 2018b).

A combination of traditional on-ground observations with remote sensing increased opportunities in outbreaks monitoring. Thus, medium-resolution Landsat scenes $(30 \times 30 \mathrm{~m}$ pixel) were successfully applied for detecting and mapping conifer defoliation by SSM (Kharuk et al. 2003). Coarse-resolution Terra/MODIS and SPOT Vegetation data (250-1000 m pixel size) were used in the analysis of large scale insect-caused forest mortality (Spruce 2011; Kharuk et al. 2009; Eklundh 2009). In this study, we combined remote sensing and climate variables' data analysis with on-ground observations, historical records, and GIS techniques. The goal of this paper is to study the impact of regional climate change on the SSM outbreaks in alpine and northern ranges. We hypothesized that warming promoted shifts of elevational and northern outbreak boundaries. We analyzed SSM outbreaks chronology in Central Siberia since the $19^{\text {th }}$ century with the emphasis on the latest (2018-2019) outbreak.

We were seeking the answers to the following questions:

(1) How does outbreak occurrence relate to climate variables?

(2) How do outbreak onset and dynamic relate to topography features?

(3) How does climate change affect alpine and northern limits of SSM outbreaks?

\section{Materials and Methods}

This study is based on the combined analysis of satellite (Landsat and Terra/MODIS) time series scenes, temperature and moisture variables, onground survey within the latest SSM outbreak area and historical record of outbreaks occurrence.

\subsection{Study Area}

The study area is the Siberian pine and fir 
ranges in Central Siberia which included SSM outbreaks described in the scientific literature (Figure 1). We are focusing on the analysis of the latest SSM outbreak that occurred in 2018-2019 (site \#1 in Figure 1). That outbreak was located within the northern part of East Sayan Mountains with the highest elevations about $1,700 \mathrm{~m}$. Siberian pine and fir forests occupied belt within elevations c. 300-1600 $\mathrm{m}$ a.s.l.. Lower elevations are occupied by mixed birch (Betula pendula) and aspen (Populus tremula) stands. Alpine foresttundra ecotone is formed by Siberian pine, larch (Larix sibirica) and fir.

\subsection{On-ground studies}

On-ground surveys were conducted by entomologists from the Krasnoyarsk Center of Forest protection during 2019 (June-October). The survey was planned based on the preliminary Landsat-derived map of stands' defoliation. Within that map test plots (76 total) were randomly selected. Within each plot, seven model trees from the upper canopy were selected and georeferenced (total $N=533$ ). Trees "shake-off" method was used for larva counting and age group determination. Along with that, an inventory data (tree's height, dbh (diameter at breast height), species composition, stands closure and forest type) were obtained for each test plot from the forest inventory database. During late fall larvae were counted within on-ground cover within tree crown projections (3 tests plot with size of $0.25 \mathrm{~m}^{2} ; N=$ 33). The first on-ground observations of the SSM outbreak was made by local foresters and referred to in June 2019. In September 2019 the larva density reached 2200-2400 per tree within the heavily defoliated (> 75\%) stands. Within low defoliated $(<10 \%)$ stands larvae' number was highly variable (5-300 per tree). In 2019 the silkmoth outbreak was in the eruptive phase of the cycle. By the end of 2019, the outbreak area was estimated as 32000 ha.

\subsection{SSM outbreaks range boundaries calculations}

SSM outbreak range, according to empirical observations, is limited by cumulative active $\left(>+10^{\circ} \mathrm{C}\right)$ air temperatures. In previous studies, it

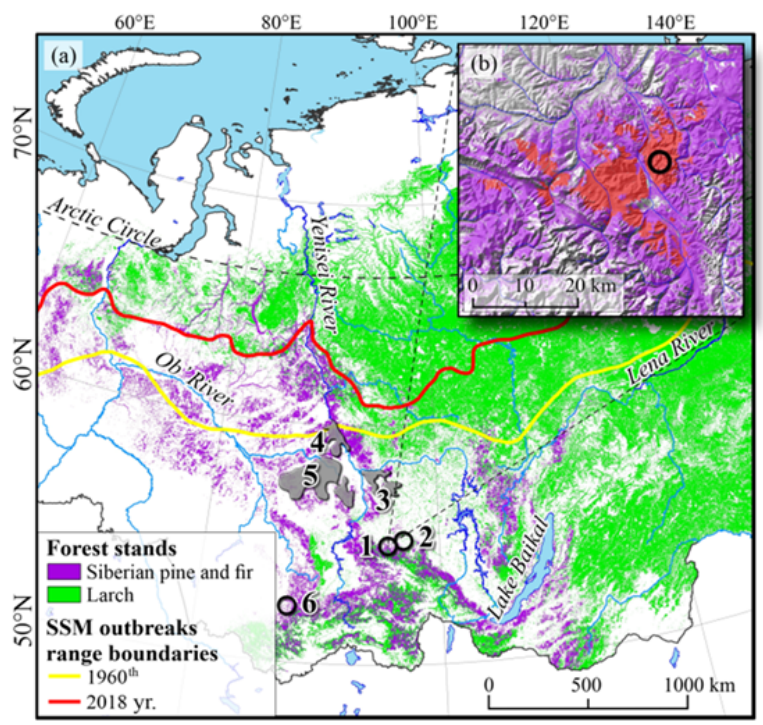

Figure 1 The study area (a) included Siberian pine and fir dominant stands. 1: location of the latest (2018-2019) silkmoth outbreak which was analyzed in this paper; 2-6: locations of former Siberian silkmoth outbreaks (2: 20022003; 3: 1994-1996; 4: 2015-2017; 5: 1953-1957; 6: 20112014 yrs.). Siberian silkmoth (SSM, Dendrolimus sibiricus Tschetv.) outbreaks (1, 2 and 6) are shown by black circle and (3-5) shown by contours. Map in the upper right corner (b) showing the studied outbreak 1: Dead and alive stands are indicated by red and purple, correspondingly. Outbreak onset location is indicated by the circle on the (a).

was found that northern silkmoth outbreak boundary was approximated by $\Sigma\left(t>+10^{\circ} \mathrm{C}\right)=$ $1200^{\circ} \mathrm{C}$ isoline (Rojkov 1965), i.e., the cumulative temperature that must be reached in an area to be suitable for the SSM outbreaks. The outbreak's boundaries location, both elevational and latitudinal, should be shifting due to warming. For calculations of expected warming-induced silkmoth outbreaks' boundaries shift we used the above mentioned criterion (Rojkov 1965).

\subsection{Eco-climate variables}

Based on our own and the literature's data, we included the main climate variables into the analysis: daily and monthly air temperature, a sum of active $\left(>+10^{\circ} \mathrm{C}\right)$ temperatures, monthly precipitation and growing period length (in days). Along with that, surface moisture content was also considered because this variable is essential for caterpillar survival (Kondakov 2002). Climate variables values were obtained from the Climate Research Unit Time-Series database (CRU TS 4.03; 1901-2018; spatial resolution $0.5^{\circ} \times 0.5^{\circ}$; https://crudata.uea.ac.uk; Harris et al. 2014). Daily 
air temperature data and surface moisture content (o-2 cm layer) were calculated using the MERRA2 database (Modern-Era Retrospective analysis for Research and Applications; period 1980-2018; spatial resolution $0.625^{\circ} \times 0.5^{\circ}$; https://gmao.gsfc. nasa.gov/reanalysis/MERRA-2; Gelaro et al. 2017). Air drought was analyzed based on the SPEI data (https://spei.csic.es/map/maps.html; spatial resolution $0.5^{\circ} \times 0.5^{\circ}$ ). The SPEI (Standardized Precipitation-Evapotranspiration Index) indicates the difference between precipitation and potential evapotranspiration (Beguería et al. 2014). We used an analysis of variance (ANOVA; Moore et al. 2017), $t$-test and nonparametric Mann-Whitney test to assess the effect of climatic variables on the area defoliated. Then to determine the change in the annual defoliation, we used segmented linear regression analysis (SegReg algorithm https://www. waterlog.info/segreg.htm) to identify breakpoints in the defoliation time series. Statistical analysis was applied using software Statsoft Statistica (http://statsoft.ru) and Microsoft Excel.

\subsection{Satellite data}

A time-series of Landsat- 8 scenes $(N=14$, period 2013-2019) and Terra/MODIS data (16days averaged composites, $N=166$, MaySeptember, 2002-2018) were used in the outbreak analysis (https://earthexplorer.usgs.gov). Atmospherically corrected Landsat data were converted to reflectance by the LaSRC algorithm (https://www.usgs.gov/media/files/land-surfacereflectance-code-lasrc-product-guide). The mask of Siberian pine and fir stands before the outbreak was generated based on the Landsat scene dated by 2013. The maximum likelihood classification with the threshold procedure $(p=0.05)$ was applied. The generated mask had high accuracy (overall 94.7 \%; overall $\operatorname{KHAT}(\kappa)$-statistics $=0.89 ; 276$ test points). Dead and damaged stands were identified based on the NDII (Normalized Difference Infrared Index) infrared index (Hardisky et al. 1983):

$$
\text { NDII }=(\text { NIR }- \text { SWIR1 }) /(N I R+\text { SWIR1 })
$$

where NIR are signatures in the near-infrared (851-879 $\mathrm{nm}$ ) and shortwave infrared (SWIR1; 1566-1651 nm) channels, correspondingly. Earlier NDII was successfully applied for stressed and dead stands detection (Townsend et al. 2012;
Kharuk et al. 2019). Three categories of the stands were considered: alive, damaged $(\sim 30 \%-70 \%$ of the dead trees) and dead ( $>70 \%$ of the dead trees). These categories were detected basing on the sample sets generated based on high-res satellite images taken from the Google Maps, Yandex Maps, and ESRI ArcGIS World Imagery. Quality and onground resolution $\left(0.5^{-2} \mathrm{~m}\right)$ of these images allowed to detect the above mentioned three categories based on the expert interpretation. Landsat-derived classification of these stands was based on the region growing algorithm (Hexagon 2019). Then the histogram of NDII values was calculated, and high (percentile 97.5\%) and low (percentile 2.5\%) margins of NDII distribution were found. The resulted histogram showed a good differentiation of alive and (dead + damaged) stands (Figure 2). Then NDII values within range $0.1 \geq$ NDII $<0.3$ were used to detect the dead and damaged stands. The accuracy of the resulted classification was high (overall $\operatorname{KHAT}(\kappa)$-statistics $\kappa=0.89$; overall accuracy 93\%; 415 test points). Along with that, the time-series of the Enhanced Vegetation Index (EVI) was used for detection outbreak onset. That index, as well as NDII, is sensitive to vegetation vigor and stand's dieback (Kharuk et al. 2013a, b). The EVI values were extracted from MODIS products (MYD13Q1; https://earthdata.nasa.gov; Didan and Huete 2015). Although these data had a lower resolution (250 $\mathrm{m}$ vs $30 \mathrm{~m}$ of Landsat), it allowed to investigate outbreak dynamics with the 16-days resolution, whereas Landsat scenes were often of poor quality due to cloud cover. EVI is defined as:

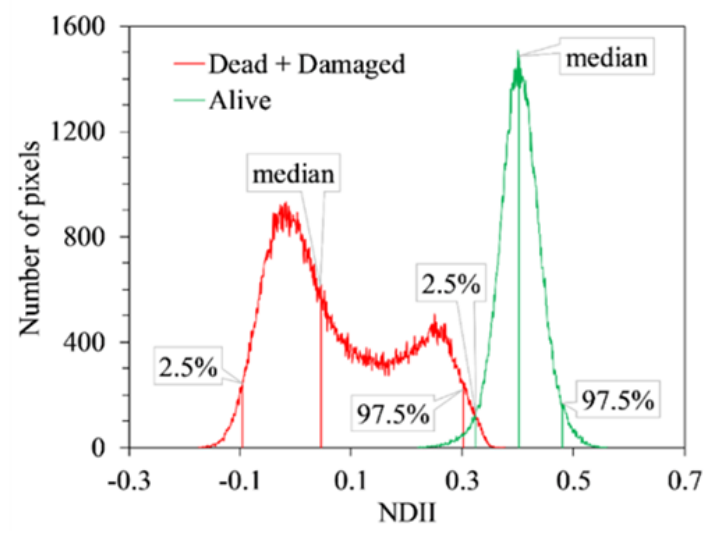

Figure 2 Dead + damaged and alive stands have significantly different NDII (Normalized Difference Infrared Index) signatures. Median and percentiles (2.5\% and 97.5\%) locations are shown. 


$$
\begin{array}{r}
\mathrm{EVI}=G \times\left(\rho_{\text {NIR }}-\rho_{\text {red }}\right) \times\left(\rho_{\text {NIR }}-C_{1} \times \rho_{\text {red }}+\right. \\
\left.C_{2} \times \rho_{\text {blue }}+L\right)^{-1}
\end{array}
$$

where $\rho_{\text {NIR }}, \rho_{\text {red }}$ and $\rho_{\text {blue }}$ are reflectance in the near-infrared $(620-670 \mathrm{mn})$, red $(841-876 \mathrm{mn})$ and blue (459-479 nm) bands; $L, C_{1}, C_{2}, G$ are correction coefficients (Huete et al. 1999). The differences $(\Delta)$ between EVI values within the initial outbreak location and healthy stands were analyzed.

\subsection{GIS analysis}

GIS analysis was based on the SRTM (Shuttle Radar Topography Mission) digital elevation model (DEM; 30-m spatial resolution; vertical accuracy 7-16 m) (Mukul et al. 2015; Overview of Global DEM 2017). Stands mortality was analyzed versus elevation, exposure, slope steepness, and terrain curvature (concave/convex sites). Non-uniformity of landscape features distributions within the study area may lead to bias in geospatial analysis of stands' mortality. The following data normalization was used to remove that bias:

$$
A_{c, i}=100 \times S_{c, i} / F_{c, i}
$$

where $i$ is the $i$-th class of the relief feature $c$ (elevation, slope, aspect, curvature), $n$ is the number of classes of the relief feature $c$ (for example, there were eight classes for aspects northern slopes $\left(\left[0^{\circ}-22.5^{\circ}\right),\left[337.5^{\circ}-360^{\circ}\right]\right)$, north-eastern slopes $\left[22.5^{\circ}-67.5^{\circ}\right)$, eastern slopes $\left[67.5^{\circ}-112.5^{\circ}\right)$, etc. $)$.

ESRI ArcGIS (https://desktop.arcgis.com) and Erdas Imagine (https://www.hexagongeospatial. com/products/power-portfolio/erdas-imagine) were used for satellite data analysis and spatial data processing.

\section{Results}

\subsection{The chronology of Siberian silkmoth outbreaks}

The analysis of published historical data (since the $19^{\text {th }}$ century) indicated that until the mid of $20^{\text {th }}$ century large scale outbreaks were dominant (with mean area $\sim 1,200,000$ ha; Figure 3). Since the mid of 1950, a negative trend in the outbreak area was observed. That was caused by the decrease in the total area of Siberian pine and fir dominant stands

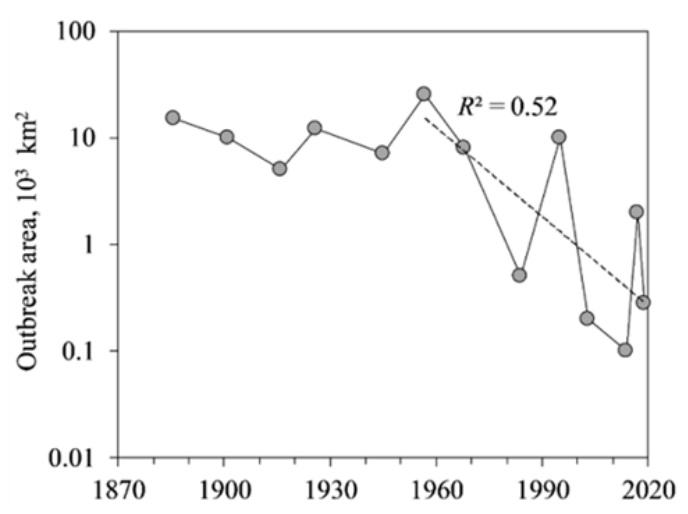

Figure 3 Historical data of Siberian silkmoth outbreaks indicated the decrease of outbreaks' area since 1950 (based on the published data: Kondakov 1974, 2002; Kharuk et al. 2003, 2016). Exponential regression, $R^{2}$ is significant at $p<0.01$. A breakpoint (1958 yr.) was identified based on the SegReg algorithm.

and stands' fragmentation due to previous outbreaks, wildfires, and clearcuts. The mean period between outbreaks was $11 \pm 3$ yrs (Figure 3 ).

\subsection{The temporal and spatial dynamics of the outbreak}

The outbreak onset was referred to June 2019 according to the on-ground observations. Meanwhile, according to the satellite data (vegetation index $\Delta$ EVI chronology), the outbreak onset was observed in August 2018 (Figure 4a). By the end of 2019, the outbreak spread over 32,000 ha (Figure 4a).

The initial outbreak site was located on the southeast gentle $\left(\sim 10^{\circ}\right)$ concave slopes at an elevation of about $500 \mathrm{~m}$ (Figure 5). Then mortality spreads to elevations up to $\sim 750 \mathrm{~m}$ and to steeper ( up to $30^{\circ}$ ) concave and convex slopes (Figure $5 \mathrm{a}-\mathrm{c}$ ). Downhill mortality migration was limited by lack of Siberian pine and fir stands (below c. $400 \mathrm{~m}$ ). The majority of stands' mortality was observed on the southern slopes, whereas survived stands located on the northern slopes mostly (Figure $5 \mathrm{~d}$ ).

\subsection{Eco-climatic conditions preceded the SSM outbreak}

We analyzed monthly thermic and moisture parameters before the silkmoth outbreak with monthly resolution (analyzed period 1-5 yrs.) versus reference period (2010-2014). The periods 
from April till October are the months of silkmoth activity at the study site. We found that best correlations were observed for the period of three years before the outbreak onset (i.e., 2015-2017). It was observed that in the years preceding the outbreak the sum of active temperatures $\left(>+10^{\circ} \mathrm{C}\right)$,

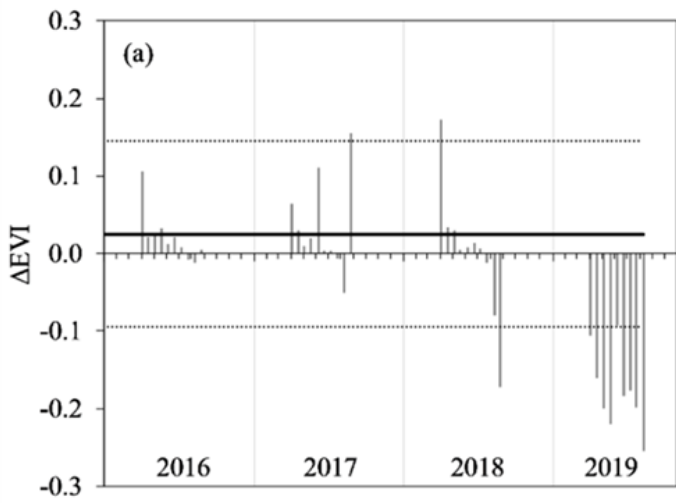

the number of days with active temperatures and atmospheric drought (indicated by SPEI) increased, whereas surface layer moisture content decreased (Figure 6). Along with that, the July precipitation decrease was also observed.

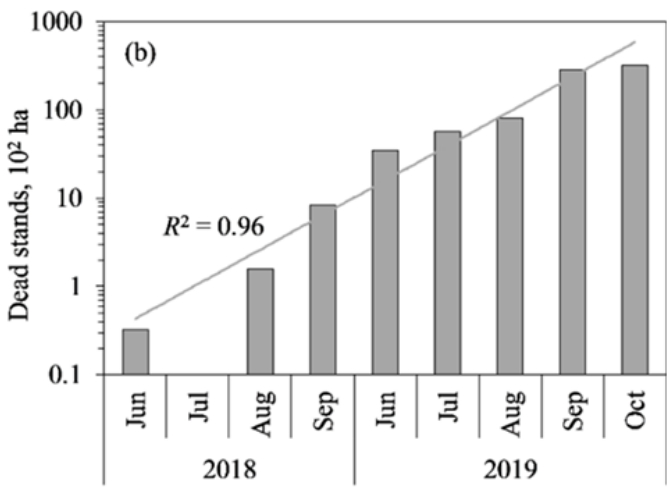

Figure 4 (a) $\triangle$ EVI (EVI difference between primary outbreak location and alive stands) indicated outbreak onset in August 2018 (based on the SegReg algorithm). A mean $\Delta$ EVI and $3 \sigma$ are indicated by solid and dotted lines, correspondingly. (b) Dead stands' area dynamics (exponential model, $R^{2}$ significant at $p<0.01$ ).
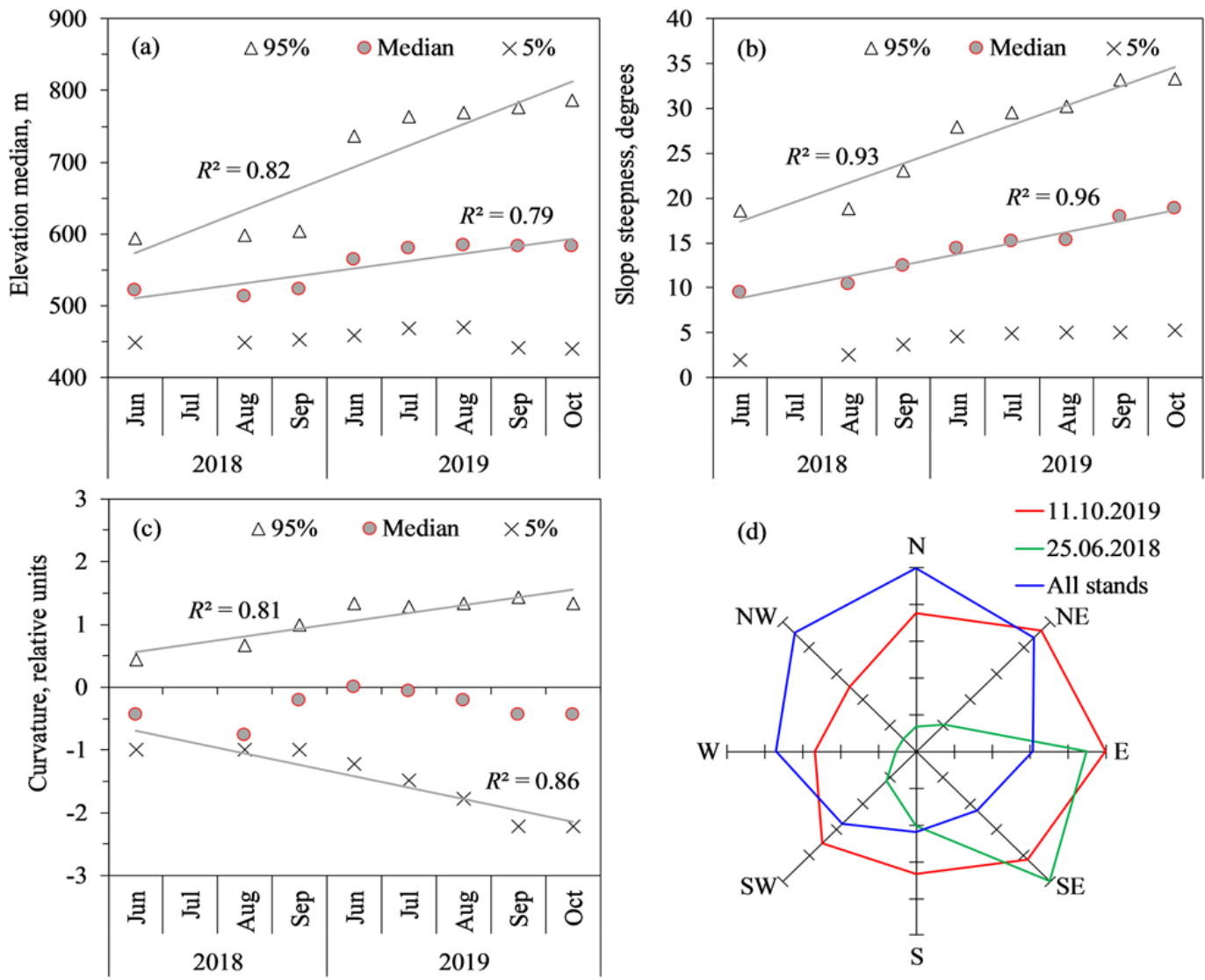

Figure 5 Dead stand normalized area distributions and dynamics (NDII (Normalized Difference Infrared Index) derived) with respect to relief features: (a) elevation, (b) slope steepness and (c) terrain curvature. Linear regressions $\left(R^{2}\right)$ shown for medians, $5 \%$ and $95 \%$ percentile (i.e., for median, upper and lower variables value). (d) The primary (green) outbreak location area and total (red) outbreak area occurred mainly on the south-eastern slopes, whereas all stands (blue) located on the northwestern slopes. Unit values are given in relative units (see section 1.6). 

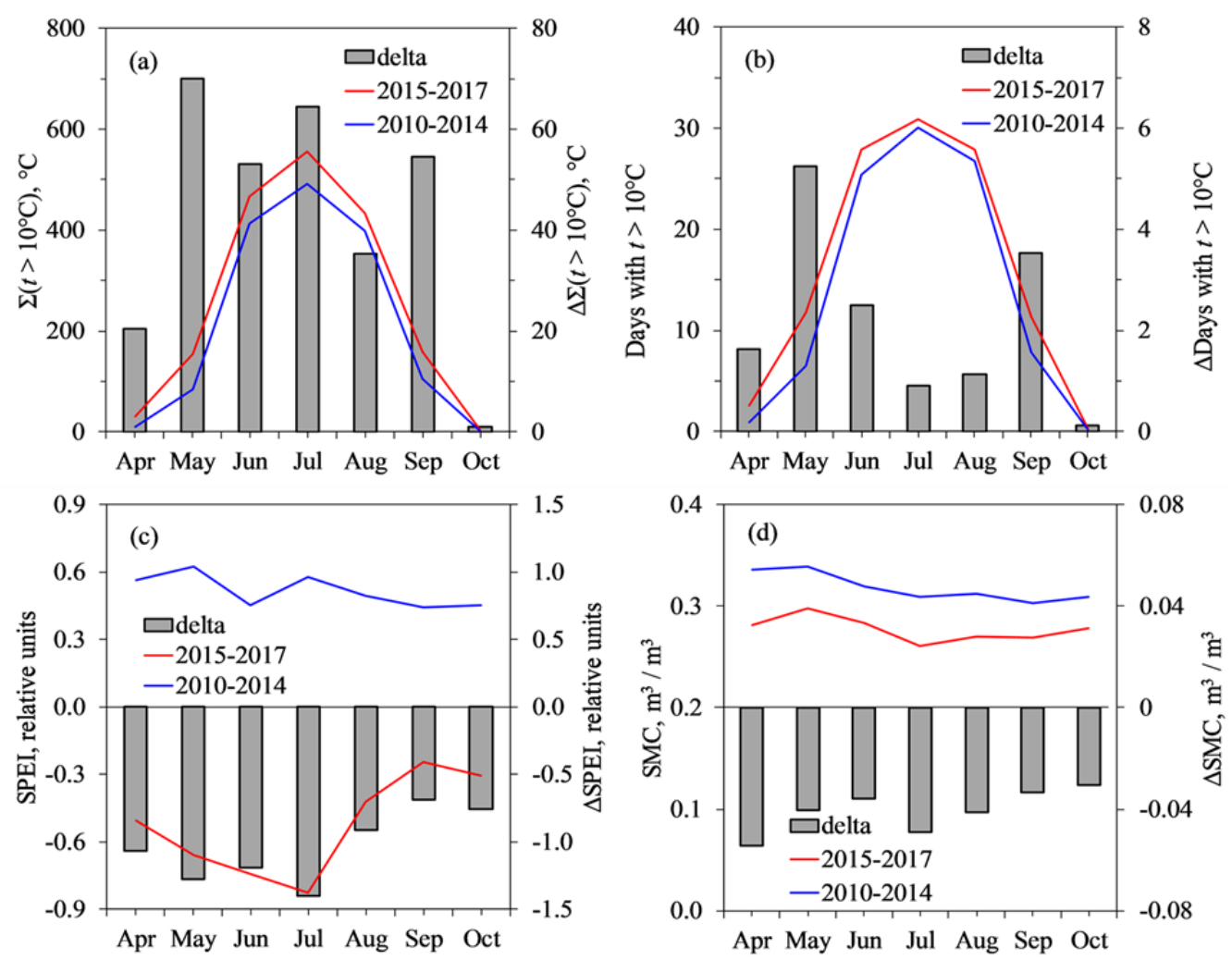

Figure 6 Eco-climatic variables in the pre-outbreak years (2015-2017) versus background period (2010-2014). Deltas are the differences between variables in (2015-2017) vs (2010-2014). (a) the sum of active temperatures $\left(t>+10^{\circ} \mathrm{C}\right)$; (b) days with air temperature $>+10^{\circ} \mathrm{C}$, (c) drought index SPEI (Standardized PrecipitationEvapotranspiration Index), (d) surface layer $(\sim 2 \mathrm{~cm})$ moisture content (SMC). For the total April-October period all deltas significantly different ( $p<0.01 ; F>7.7$; ANOVA statistic). For April and May deltas significantly different at $p<0.05$ ( $t$-test and Mann-Whitney test). SPEI decrease means drought increase by definition.

\subsection{SSM outbreaks' upper and northern boundaries migration}

Since the catastrophic outbreak during 19531957 (2,500,00o ha dead stands; Kharuk et al. 2003), the upper limit of silkmoth outbreaks observed shifted upward on c. $+370 \mathrm{~m}$. Along with that, the mean northern outbreak potential boundary shifted about $300 \mathrm{~km}$ northward (Figure 7).

Within Altai-Sayan Mountain Country, the mean upward shift of outbreaks' elevational boundary was c. +150 m since 1980 (Figure 8a). Similarly, the silkmoth northern outbreak potential boundary shifted 250$500 \mathrm{~km}$ since delineated in 1960 (Figure 1).

\section{Discussion}

With warming, the elevational upward shift of insects' outbreak ranges was inevitable. We now observe that the phenomenon in the Siberian
Mountains, where the upper limit of SSM outbreaks reached elevations of about $750 \mathrm{~m}$ a.s.l., moved about +370 m upward since the mid of 1950 . Within the whole Altai-Sayan Mountain Country, the mean potential outbreaks boundary is now located at about $150 \mathrm{~m}$ upward in comparison with the 1980-1990 reference period. Thus, warming promotes Siberian silkmoth migration into elevations where previously outbreaks were impossible due to low temperatures. Notably, similar insect migration along an elevation gradient is also reported in Western Hemisphere in the US forests (Millar and Stephenson 2015). Alongside upward migration, the potential northern boundary of SSM outbreaks shifted about 250-500 km northward in comparison with its location in 1960. The documented northward shift was about one latitude degree during the latest catastrophic SSM outbreak (in 2014-18) when $\sim 800,000$ ha of stands were killed (Kharuk et al. 2018b). 


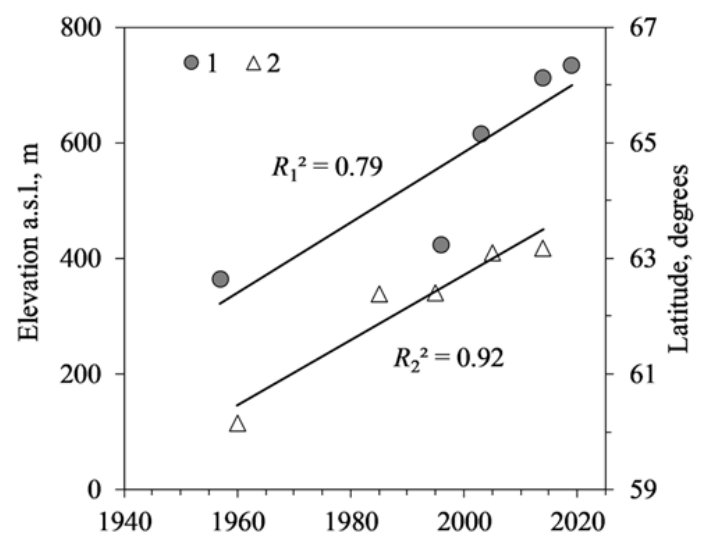

Figure 7 Since the mid of the $20^{\text {th }}$ century Siberian silkmoth (SSM) outbreaks' elevational boundary shifted to higher elevations, and outbreaks' northern limit shifted to higher latitudes. 1 -the highest elevational outbreaks' location; 2 -the mean northern latitude potential outbreaks' boundary location. Linear trends are significant at $p<0.05$. The historical data were based on the GIS-analysis of the known SSM outbreaks published in the literature (Kondakov 1974, 2002; Kharuk et al. 2003, 2016).

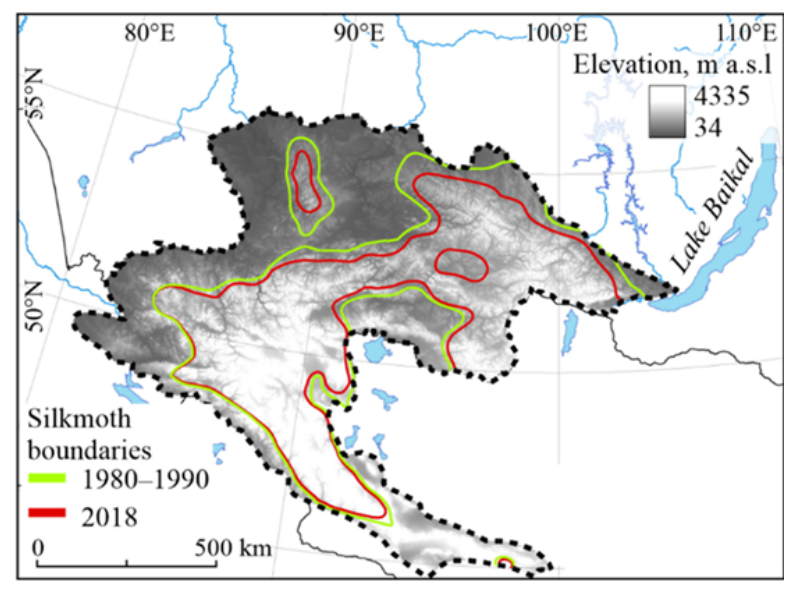

Figure 8 Silkmoth upper outbreak boundary migration in Altai-Sayan Mountain Country in Central Siberia (2018 vs 1980-1990).

Silkmoth outbreak onset in the Sayan Mountains was promoted by thermic and moisture anomalies during the pre-outbreak years, when active air temperatures and air drought were increased, whereas on-ground layer moisture decreased. These changes were especially noticeable at the beginning of the growing period, the crucial time interval for caterpillar survival (Kondakov 2002). Larvae start going out from the on-ground layer from the end of April to the beginning of May. Namely, in that period, an increase in air temperature and the number of days with active temperatures as well as drought were observed (Figure 6). Warm and dry spring without late frost and dry on-ground layer are favorable for caterpillar survival in spring. Otherwise, spring rains and late frosts would cause the insect population to die out. Warming also leads to an increase in the growing period, i.e. prolongation of larvae' active feeding period. As a result, we observed a switch of the silkmoth population from a two-year to a one-year generation cycle. With predicted climate warming and aridity increase in the southern taiga zone (Pachauri et al. 2014), these favorable conditions will become more frequent.

Mountain topography significantly affected the primary SSM outbreak location and the following spatial outbreak distribution. The outbreak onset occurred at the southeast-facing gentle slopes within middle (about $500 \mathrm{~m}$ ) elevations, the habitats which are favorable for the SSM population between the outbreaks' period. With outbreak development, tree mortality spreads to steeper slopes, higher and lower elevations and partly on the colder north-facing slopes. This finding supported similar observations on the dynamics of former SSM outbreaks in the AltaiSayan Mountain Country (Kharuk et al. 2009, 2016, 2018b). Meanwhile warming provides an additional food base at higher elevations due to tree growth increment and stand closure increase, as well as an upward treeline advance.

The historical record of SSM outbreaks indicated a damaged area decrease since the mid of the $20^{\text {th }}$ century. Before the instrumental (airsurvey and satellite-based) monitoring small-size outbreaks may have been missed of course. Nevertheless, the negative trend is observed since the mid of 1950, when air-survey was widely applied in forest monitoring (Figure 3). Currently, within the southern part of Siberian pine and fir ranges (i.e., southward of 60 parallel, Figure 1) large-scale outbreaks are hardly possible due to the silkmoth "food base" decrease and stands' fragmentation by former outbreaks, clear-cuts, and wildfires. Thus, after the outbreak in 1953-1957 (stands' mortality on about 2,400,000 ha) more than one-third of the outbreak area has not yet been reforested by Siberian pine and fir. Moreover, now fir and Siberian pine ranges in the southern lowlands are shrinking due to increased aridity in combination with pest outbreaks. Moisture- 
sensitive fir and Siberian pine are being substituted by tolerant species (e.g., Pinus sylvestris and Larix sp.) (Kharuk et al. 2018). Meanwhile, warmingfacilitated alpine and northern SSM outbreak boundary migration are adding new stands into silkmoth "food base". These northern and highelevation fir and Siberian pine forests were not still experienced silkmoth attacks or massive clear-cuts. Thus, the latest catastrophic SSM outbreak was possible also due to silkmoth expansion into northward stands (Kharuk et al. 2017). Northerly expansion of outbreaks' boundary adding a vast area of larch-dominant stands (Larix sibirica, $L$. dahurica) to the silkmoth "food base" (Figure 1), because SSM feeds also on the larch needles. Larch species are rather resistant to silkmoth attacks and can survive complete defoliation, although repeating defoliation caused stands' mortality. In addition, warming leads to a increase in stands' density within northern and highland conifers range, therefore increases the potential silkmoth food base (Kharuk et al. 2018a).

The SSM outbreaks northward and uphill migration also facilitated the migration of the secondary pests, i.e., bark-beetles. Those insects (such as a Monochamus urussovi or an aggressive invader Polygraphus proximus) attack weakened trees and killed stands. The other consequence of SSM range expansion will be an increase in wildfires danger via "fuel" accumulation in killed stands and via expansion of grass communities that served as a fire ignition material for the spring fires (Kharuk and Antamoshkina 2017).

Finally, the methodology described in this paper has some potential applications for decisionmaking and pest management. (1) For early warning of insect outbreak that is essential for insect population suppression. Data obtained indicated that EVI-based analysis could detect an outbreak onset about one year earlier than on-ground studies. That is especially important in pest monitoring over vast taiga forest with low on-ground "manpower" and resources. Along with that, knowledge of the relationship between an outbreak onset and

\section{References}

Alfaro RI, Campbell EM, Hawkes BC (2010) Historical frequency, intensity and extent of mountain pine beetle disturbance in British Columbia. Mountain Pine Beetle Working Paper 2009-30. Victoria, BC., Canada: Natural Resources Canada, Canadian Forest Service, Pacific Forestry Centre. p 52. topography features could be applied for selecting priority monitoring areas. (2) Based on the detected areas of stands' decline mortality, forest managers may generate a recommendation for logging. That will allow to harvest woods before the trees decay, as well as it will prevent outbreaks of bark beetles which feed on the weakened and dead trees. Meanwhile, for practical decision-making and pest management, an additional study is necessary.

\section{Conclusion}

Warming promoted SSM outbreaks exceed the geo-climatic barrier in the mountains. Since mid of 1950, the elevational outbreak boundary shifted +370 m uphill. The outbreak onset is linked with warmer and dryer pre-outbreak years with higher active temperatures, the increased air drought and decreased on-ground cover moisture content. These thermal and moisture anomalies are especially pronounced in the spring-early -summer period. The outbreak onset and dynamics depended on the topography features. The primary outbreak site was located at middle elevations on gentle relatively dry concave southeastern slopes, the habitats that are favorable for insect population between the outbreaks' period. Then the outbreak spreads uphill and downhill, and to steeper slopes. Alongside with elevation range expansion, SSM surpassed its northern historical boundary. The potential northern outbreaks boundary shifted northward on about $300 \mathrm{~km}$. Climate warming opened opportunities for SSM migration into former outbreak-free conifer stands in highlands and at northern latitudes.

\section{Acknowledgments}

This study was supported by the Russian Foundation for Basic Research, project nos. 18-45240003 and 18-05-00432.
Beguería S, Vicente-Serrano SM, Reig F, et al. (2014) Standardized Precipitation Evapotranspiration Index (SPEI) revisited: parameter fitting, evapotranspiration models, kernel weighting, tools, datasets and drought monitoring. International Journal of Climatology 34(10): 3001-3023. https://doi.org/10.1002/joc.3887 
Bentz BJ, Régnière J, Fettig CJ, et al. (2010) Climate change and bark beetles of the western United States and Canada: direct and indirect effects. Bioscience 6o(8): 602-613.

https://doi.org/10.1525/bio.2010.60.8.6

Coleman TW, Jones MI, Courtial B, et al. (2014) Impact of the first recorded outbreak of the Douglas-fir tussock moth, Orgyia pseudotsugata, in southern California and the extent of its distribution in the Pacific Southwest region. Forest Ecology and Management 329: 295-305.

https://doi.org/10.1016/j.foreco.2014.06.027

De la Giroday HC, Carroll AL, Aukema BH (2012) Breach of the northern Rocky Mountain geoclimatic barrier: initiation of range expansion by the mountain pine beetle. Journal of Biogeography 39: 1112-1123. https://doi.org/10.1111/j.1365-2699.2011.02673.x

Didan K, Huete A (2015) MYD13Q1 MODIS/Aqua Vegetation Indices 16-Day L3 Global 250m SIN Grid. NASA LP DAAC.

https://lpdaac.usgs.gov/products/myd13q1voo6 (Accessed on 9 January 2020). http://doi.org/10.5067/MODIS/MYD13Q1.006

Eklundh L, Johansson T, Solberg S (2009) Mapping insect defoliation in Scots pine with MODIS time-series data. Remote Sensing of Environment 113: 1566-1573.

https://doi.org/10.1016/j.rse.2009.03.008

Gelaro R, McCarty W, Suárez MJ, et al. (2017) The Modern-Era Retrospective Analysis for Research and Applications, Version 2 (MERRA-2). Journal of Climate 30: 5419-5454 https://doi.org/10.1175/JCLI-D-16-0758.1

Hardisky M, Klemas V, Smart R (1983) The Influences of Soil Salinity, Growth Form, and Leaf Moisture on the Spectral Reflectance of Spartina Alterniflora Canopies. Photogrammetric Engineering and Remote Sensing 49: 77-83.

Harris I, Jones PD, Osborn TJ, et al. (2014) Updated high resolution grids of monthly climatic observations - the CRU TS3.10 Dataset. International Journal of Climatology 34(3): 623642. https://doi.org/10.1002/joc.3711

Haynes KJ, Allstadt A, Klimetzek D (2014) Forest defoliator outbreaks under climate change: Effects on the frequency and severity of outbreaks of five pine insect pests. Global Change Biology 20: 2004-2018. https://doi.org/10.1111/gcb.12506

Hexagon (2019) Documentation Portal. ERDAS IMAGINE Help. Region Grow. https://hexagongeospatial.fluidtopics.net/reader/ fHoo7KrMKUViXGUeoilQuA/QsacB3KAJUdbHeDr Je97Q, accessed on 14 January 2020

Huete A, Justice C, van Leeuwen W (1999) MODIS vegetation index (MOD 13) - algorithm theoretical basis document.

http://modis.gsfc.nasa.gov/data/atbd/atbd_mod14.pdf (Accessed on 24 December 2019)

Kharuk VI, Ranson KJ, Kuz'michev VV, et al. (2003) Landsat-based analysis of insect outbreaks in southern Siberia. Canadian Journal of Remote Sensing 29(2): 286-297.

https://doi.org/10.5589/mo2-094

Kharuk VI, Ranson KJ, Im ST (2009) Siberian silkmoth outbreak pattern analysis based on SPOT VEGETATION data. International Journal of Remote Sensing: 30(9): 2377-2388. https://doi.org/10.1080/01431160802549419

Kharuk VI, Im ST, Oskorbin PA, et al. (2013a) Siberian Pine Decline and Mortality in Southern Siberian Mountains. Forest Ecology and Management 310: 312-320.

https://doi.org/10.1016/j.foreco.2013.08.042

Kharuk VI, Ranson KJ, Oskorbin PA, et al. (2013b) Climate induced birch mortality in trans-Baikal lake region, Siberia. Forest Ecology and Management 289: 385-392.

https://doi.org/10.1016/j.foreco.2012.10.024

Kharuk VI, Demidko DA, Fedotova EV, et al. (2016) Spatial and temporal dynamics of Siberian silk moth large-scale outbreak in dark-needle coniferous tree stands in Altai. Contemporary Problem of Ecology 9: 711-720.

https://doi.org/10.1134/S199542551606007X

Kharuk VI, Antamoskina OA (2017) Impact of silkmoth outbreak on taiga wildfires. Contemporary Problems of Ecology 10: 556-562. https://doi.org/10.1134/S1995425517050055
Kharuk VI, Im ST, Petrov IA (2018a) Warming hiatus and evergreen conifers in Altay-Sayan Region, Siberia. Journal of Mountain Science 15(12): 2579-2589.

https://doi.org/10.1007/s11629-018-5071-6

Kharuk VI, Im, ST, Yagunov MN (2018b) Migration of the Northern Boundary of the Siberian Silk Moth. Contemporary Problems of Ecology 11: 26-34. https://doi.org/10.1134/S1995425518010055

Kharuk VI, Shushpanov AS, Petrov IA, et al. (2019) Fir (Abies sibirica Ledeb.) Mortality in Mountain Forests of the Eastern Sayan Ridge, Siberia. Contemporary Problems of Ecology 12(4): 299-309.https://doi.org/10.1134/S199542551904005X

Koropachinskiy IYu, Vstovskaya TN (2002) Woody plants of the Asian part of Russia. Publishing House of SB RAS, Branch Geo, Novosibirsk, Russia. (In Russian)

Kolb TE, Fettig CJ, Ayres MP, et al. (2016) Observed and anticipated impacts of drought on forests insects and diseases in the United States. Forest Ecology and Management 380: 321-334. https://doi.org/10.1016/j.foreco.2016.04.051

Kondakov YP (1974) Patterns of Siberian silkmoth outbreaks. In: Ecology of forest animal population in Siberia. Nauka. Novosibirsk, Russia. pp 206-264. (In Russian)

Kondakov YP (2002) Siberian silkmoth outbreaks in Krasnoyarskii krai. In: Entomology Researches in Siberia. KF REO. Krasnoyarsk, Russia. pp 25-74. (In Russian)

Millar CI, Stephenson NL (2015) Temperate forest health in an era of emerging megadisturbance. Science 349(6250): 823-826. https://doi.org/10.1126/science.aaa9933

Moore DS, McCabe GP, Craig BA (2017) Introduction to the Practice of Statistics. 9th Edition. New York: WH Freeman. p 814.

Mukul M, Srivastava V, Mukul M (2015) Analysis of the accuracy of Shuttle Radar Topography Mission (SRTM) height models using International Global Navigation Satellite System Service (IGS) Network. Journal of Earth System Science 124(6): 1343-1357. https://doi.org/10.1007/s12040-015-0597-2

Overview of Global DEM (2017) Assessment of the current global DEMs and requirements for an updated global DEM. https://insitu.copernicus.eu/library/reports/OverviewofGlobalD EM_ior7.pdf/at_download/file (Accessed on 9 January 2020)

Pachauri RK, Allen MR, Barros VR, et al. (2014) Climate Change 2014: Synthesis Report. Contribution of Working Groups I, II and III to the Fifth Assessment Report of the Intergovernmental Panel on Climate Change. R. Pachauri and L. Meyer (Eds.). IPCC, Geneva, Switzerland. https://epic.awi.de/id/eprint/37530/1/ IPCC_AR5_SYR_Final.pdf (Accessed on 14 April 2020)

Pureswaran D, Grandpre L, Pare D, et al. (2015) Climate-induced changes in host tree-insect phenology may drive ecological stateshift in boreal forests. Ecology 96(6): 1480-1491. https://doi.org/10.1890/13-2366.1

Rojkov AS (1965) Siberian silkmoth outbreak and pest control. Moskow, Russia: Nauka. p 180. (In Russian)

Seiter S, Kingsolver J (2013) Environmental determinants of population divergence in life-history traits for an invasive species: climate, seasonality and natural enemies. Journal of Evolutionary Biology 26: 1634-1645. https://doi.org/10.1111/jeb.12159

Spruce JP, Sader S, Ryan RE, et al. (2011) Assessment of MODIS NDVI time series data products for detecting forest defoliation by gypsy moth outbreaks. Remote Sensing of Environment 115: 427437. https://doi.org/10.1016/j.rse.2010.09.013

Thompson L, Faske T, Banahene N, et al. (2017) Variation in growth and developmental responses to supraoptimal temperatures near latitudinal range limits of gypsy moth Lymantria dispar (L.), an expanding invasive species. Physiological Entomology 42: 181190. https://doi.org/10.1111/phen.12190

Townsend PA, Singh A, Foster JR, et al. (2012) A general Landsat model to predict canopy defoliation in broadleaf deciduous forests. Remote Sensing of Environment 119: 255-265. https://doi.org/10.1016/j.rse.2011.12.023

Weed AS, Ayres MP, Hicke JA (2013) Consequences of climate change for biotic disturbances in North American forests. Ecological Monographs 83: 441-470. https://doi.org/10.1890/13-0160.1 